\title{
Thoracoscopic sympathectomy for palmar hyperhidrosis and Raynaud's phenomenon of the upper limb and excessive facial blushing: a five year experience
}

\author{
Y S Rajesh, C P Pratap, A B Woodyer
}

Postgrad Med J 2002;78:682-684

See end of article for authors' affiliations

....................

Correspondence to:

Mr Y S Rajesh, Royal

Liverpool University

Hospital, Liverpool L7 8XP,

UK; rajyag@hotmail.com

Submitted

16 January 2002

Accepted 19 June 2002

\begin{abstract}
Primary hyperhidrosis of the palms, face, and axillae has a strong negative impact on social and professional life. A retrospective analysis of 40 laparoscopic transaxillary thoracic sympathectomies performed in a district general hospital over a five year period was undertaken in order to determine the effectiveness of this procedure. A postal questionnaire was sent to all patients to assess the benefit from the operation; postoperative pain and time off work were collated. Immediate failure was noted in three patients, of whom two later underwent successful reoperation. Recurrence was noted in three patients $(8 \%)$. Though immediate complications were minimal, the major long term postoperative morbidity was compensatory hyperhidrosis on the back, chest, and thigh $(77 \%)$ along with gustatory sweating over the face (22\%). Thoracoscopic sympathectomy is a safe, effective, and minimally invasive surgical treatment for hyperhidrosis, Raynaud's phenomenon of the upper limb, and excessive facial blushing; however, the chance of long term compensatory hyperhidrosis is high.
\end{abstract}

$\mathrm{S}$ weating that exceeds the need for normal thermoregulation of the skin is called hyperhidrosis. The condition affects between $0.6 \%$ to $1.1 \%$ of the population. ${ }^{12}$ Primary hyperhidrosis usually starts in childhood and is of unknown aetiology. Secondary hyperhidrosis may be due to various endocrine conditions (hyperthyroidism, phaeochoromocytoma, diabetes mellitus, acromegaly, hyperpituitarism, or carcinoid syndrome), central neurological lesions, autonomic neuropathy, gout, or local lesions-for example, chronic infection.

Management of primary hyperhidrosis includes nonoperative and operative measures. Non-operative approaches include application of topical agents (for example, aluminium chloride, gluteraldehyde, and tannic acid), iontophoresis, systemic anticholenergic medication, and psychotherapy. ${ }^{3}$ Operative measures include excision of axillary sweat glands, suction assisted lipolysis, and sympathectomy. In about 30\% to $40 \%$ of patients medical management fails to afford any appreciable benefits. In such cases surgery can provide permanent benefit. Upper dorsal sympathectomy is now the treatment of choice for intractable hyperhidrosis. In addition, it is also of established benefit in severe Raynaud's phenomenon and major causalgia as well as in Sudeck's atrophy. ${ }^{4-9}$

Thoracoscopic sympathectomy, since its first description by Kux in $1954,{ }^{10}$ has rendered the open operation obsolete. ${ }^{112}$ It is now the preferred method for treating intractable palmar hyperhidrosis. ${ }^{13-15}$ In this study we report the clinical outcome as well as the results of a postal audit of thoracoscopic sympathectomy performed for palmar hyperhidrosis, Raynaud's phenomenon of the upper limb, and excessive facial blushing.

\section{SUBJECTS AND METHODS}

A retrospective analysis of all thoracoscopic sympathectomies performed in a district general hospital over a five year period was undertaken. A postal questionnaire was sent to all the patients to assess the benefit from the operation, intensity and duration of postoperative pain, wound problems, postoperative excessive sweating on chest, back, and face, and absence from work.

\section{Surgical technique}

The procedure was performed under general anaesthesia using a double lumen endotracheal tube..$^{15}{ }^{16}$ The patient was placed in the supine position with both arms abducted to 90 degrees. An artificial pneumothorax was established by insufflating 0.5 to 1 litre of carbon dioxide through a Veress needle in the fourth intercostal space anterior to the midaxillary line, having first disconnected the ipsilateral portion of the endotracheal tube from the ventilator. A small incision was made in the fourth intercostal space in the anterior axillary line and a zero degree laparoscope was introduced through a $10 \mathrm{~mm}$ port. A second $10 \mathrm{~mm}$ port was also introduced in the same intercostal space in midaxillary line to allow passage of insulated diathermy forceps. The sympathetic chain was visualised under the parietal pleura running down over the necks of second, third, fourth, and fifth ribs. Coagulation diathermy current is applied to the second, third, and fourth ganglia and intervening sympathetic chain.

\section{RESULTS}

A total of 40 thoracic sympathectomies were conducted over the five year period in 26 patients. There were 12 bilateral procedures, 14 unilateral procedures, and two redo procedures. There were nine male and 17 female patients. The mean age of the patients was 30.3 years (range $15-41$ years). The indication for operation is shown in table 1 . Immediate failure of operation was noted in three patients (7\%) and two of them later underwent successful reoperation within three months. The mean length of stay in the hospital was 2.01 days (range 1-6 days). The mean duration of the operation was 43.78 minutes (range 20-72 minutes). Postoperatively one quarter of patients had residual pneumothorax, which did not require drainage (table 2). Haemothorax was minimal and did not need draining. One patient developed pleural effusion, which needed readmission and drainage. In one patient with Raynaud's phenomenon, the ulcer on the fingertip healed after the sympathectomy. One of the patients, who underwent surgery for excessive facial blushing, complained of lack of facial sweating on the operated side. 
Table 1 Indications for surgery

\begin{tabular}{lll}
\hline Indication for surgery & No of patients & No of procedures \\
\hline Hyperhidrosis & 18 & 30 \\
Palmar & 2 & 2 \\
Axillary/palmar & 2 & 2 \\
$\quad$ Reoperation & 3 & 3 \\
Raynaud's phenomenon & 3 & 3 \\
Facial blushing & 3 \\
\hline
\end{tabular}

Table 2 Postoperative complications

\begin{tabular}{ll}
\hline Complication & No of patients (\%) \\
\hline Pneumothorax requiring UWS drain & 0 \\
Pnuemothorax not requiring UWS drain & $10(25)$ \\
Haemothorax & $2(5)$ \\
Horner's syndrome & $2(5)$ \\
Surgical emphysema & $1(2)$ \\
Pleural effusion & $1(2)$ \\
Chest infection & $2(5)$ \\
\hline
\end{tabular}

UWS, underwater seal.

Table 3 Sites affected by postoperative compensatory hyperhidrosis

\begin{tabular}{ll}
\hline Site affected & No of patients (\%) \\
\hline Chest & $6(26)$ \\
Back & $10(43)$ \\
Thigh/leg & $6(26)$ \\
Face/gustatory sweating & $5(22)$ \\
Opposite palm & $5(22)$ \\
\hline
\end{tabular}

Twenty three of the 26 patients $(88 \%)$ responded to the postal questionnaire. About half (52\%) of the patients suffered severe postoperative pain for three or more days. The major long term morbidity was excessive sweating on the back, chest, and thigh $(77 \%)$ along with gustatory sweating over the face (table 3). Time off work varied from two to four weeks. About $65 \%$ patients were happy with the results of operation and the benefits lasted for more than six months. The mean (SD) follow up time was 29.08 (21.58) months (95\% confidence interval 20.07 to 38.09 months, range 2-65 months). Of the 36 procedures conducted for hyperhidrosis, three $(8 \%)$ patients had recurrence of symptoms. One patient had recurrence within a month of surgery and the other two had benefit for two years.

\section{DISCUSSION}

The aetiology of primary hyperhidrosis still remains elusive. It is more common in young women, some of whom suffer severe and obvious dripping of the hands. This has an impact on various aspects of life including education, occupation, social interaction, and psychological problems.

Non-operative management, including topical agents, has proved disappointing. ${ }^{3}$ Thoracic sympathectomy is now an established treatment for palmar hyperhidrosis. With the introduction of high resolution videoendoscopy and closed rod-lens instrumentation, endoscopic thoracic sympathectomy has become the treatment of choice compared with the open procedure. ${ }^{1314}$ The endoscopic technique is associated with less postoperative morbidity and better cosmetic scarring when compared with open procedure. ${ }^{11}$

Upper dorsal sympathectomy reduces the peripheral vascular resistance, hence increasing the blood flow in the peripheral vasculature. The thoracoscopic approach enables clear delineation of the sympathetic chain and the ganglia including the collateral branches (Kuntz's nerves). Better visualisation of the stellate ganglion and its preservation may avoid the sequel of Horner's syndrome. In our series we had a $5 \%$ incidence of postoperative Horner's syndrome. This probably reflects our technique of applying coagulatory diathermy to the second ganglion downwards. Furthermore, T2 sympathectomy results in reduction of facial sudomotor activity. The innervation of head and neck region is T1 to T5, while that of the upper extremities is from T2 to T4. Drott et al recommended ablation of $\mathrm{T} 2$ and $\mathrm{T} 3$ sympathetic ganglia in the treatment of palmar hyperhidrosis, $\mathrm{T} 4$ ablation in axillary hyperhidrosis, and ablation of lower part of $\mathrm{Tl}$ to treat facial involvement. ${ }^{17}$

With mean length of operation comparing favourably with other reported series, ${ }_{11}^{14}$ the mean length of stay in hospital in our series was similar to the average stay reported in the literature. ${ }^{18-20}$ Immediate postoperative complications included pneumothorax, haemothorax, and Horner's syndrome. These compare favourably with other reported series. ${ }^{11-12} 181921$ The majority of our patients complained of pain in the postoperative period lasting for more than three days. Gossot et al reported that most of their patients complained of pain in the postoperative period ranging from two to four weeks, many of whom needed morphine. ${ }^{19}$ Kopelman et al reported neuralgic pains lasting up to few months with a mean (SD) duration of 2.8 (1.9) months. ${ }^{14}$

Though endoscopic thoracic sympathectomy is quick and effective, it is associated at times with very troublesome sequelae. Paradoxically, the operation, which was performed for relief of palmar hyperhidrosis, is followed by a remarkable compensatory hyperhidrosis. The reported incidence in the literature varies from $37 \%$ to $84 \% .{ }^{11-12}{ }^{19} 21-23$ According to Shelley et al its frequency reflects the extensiveness of the denervation. ${ }^{24}$ The larger the number of glands removed from thermoregulatory control, the greater the response that one can anticipate from the remaining glands. In our series 20 patients $(77 \%)$ complained of postoperative hyperhidrosis. Gustatory phenomenon after sympathectomy has been reported widely ${ }^{182223}$; in our series five patients reported sweating over the face while eating.

The result of this postal audit has provided useful data about the possible postoperative problems. This has enabled us to improve the information given to the patients preoperatively. As the operation is intended to improve quality of life, the patients should be aware of possible postoperative sequelae. This can used as a baseline for a detailed consent form. It can also be used as a screening test to determine which patients are sufficiently motivated to undergo surgery, as well as to avoid possible medicolegal problems in future.

The vast majority of the patients who undergo sympathectomy for hyperhidrosis are pleased with the results. Careful patient selection and preoperative counselling are important to ensure a satisfactory outcome. In patients with Raynaud's phenomenon and excessive facial blushing, thoracic sympathectomy is equally beneficial.

Authors' affiliations

Y S Rajesh, Royal Liverpool University Hospital, Liverpool

C P Pratap, A B Woodyer, Tameside General Hospital,

Ashton-under-Lyne, Lancashire

\section{REFERENCES}

1 Quraishy MS, Giddings AEB. Treating hyperhidrosis. BM 1993; 306:122-2.

2 Lin TS, Fang HY. Transthoracic endoscopic sympathectomy in the treatment of palmar hyperhidrosis - with emphasis on peri-operative management (1360 case analyses). Surg Neurol 1999:52:453-7.

3 Moran KT, Brady MP. Surgical management of primary hyperhidrosis. Br J Surg 1991;78:279-83. 
4 Hederman WP. Endoscopic sympathectomy. Br J Surg 1993:80:687-8.

5 Gordon A, Collin J. Thoracoscopic sympathectomy. Eur J Vasc Surg 1994;8:247-8

6 Di Lorenzo N, Sic GS, Sileri P, et al. Thoracoscopic sympathectomy for vasospastic diseases. JSLS 1998;2:249-53.

7 Urschel HC Jr. Dorsal sympathectomy and management of thoracic outlet syndrome with VATS. Ann Thorac Surg 1993;56:717-20.

8 Drott C, Gothberg G, Cleas G. Endoscopic procedures of upper-thoracic sympathetic chain. Arch Surg 1993;1 28:237-41.

9 Nicholson ML, Dennis MS, Hopkinson BR. Endoscopic transthoracic sympathectomy: successful in hyperhidrosis but can the indications be extended? Ann R Coll Surg Engl 1994;76:311-14.

10 Kux $M$. Thoracic endoscopic sympathectomy in palmar and axillary hyperhidrosis. Arch Surg 1978;113:264-6.

11 Hasmonai $M$, Kopelman D, Schein M. Thoracoscopic versus open supraclavicular upper dorsal sympathectomy: a prospective randomised trial. Eur J Surg 1994;572(suppl): 13-16.

12 Adar R, Kurchin A, Zweig A, et al. Palmar hyperhidorsis and its surgical treatment: a report of 100 cases. Ann Surg 1977;186:34-41.

13 Byrne J, Walsh TN, Hederman WP. Endoscopic transthoracic electrocautery of sympathetic chain for palmar and axillary hyperhidrosis. Br J Surg 1990;77:1046-9.

14 Kopelman D, Hasmonai $M$, Ehrenreich $M$, et al. Upper dorsal thoracoscopic sympathectomy for palmar hyperhidrosis: improved intermediate-term results. J Vasc Surg 1996;24:194-9.

15 Andrews SM, Bras P, Rennie JA. One lung ventilation endoscopic transthoracic sympathectomy. J R Coll Surg Edinb 1994;39:350-2.
16 Jedeikin $\mathbf{R}$, Olsfanger $D$, Shachor $D$, et al. Anaesthesia for transthoracic sympathectomy in the treatment of upper limb hyperhidrosis. $\mathrm{Br} J$ Anaesth 1992;69:349-51.

17 Drott C, Gothberg G, Cleas G. Endoscopic transthoracic sympathectomy: an efficient and safe method for the treatment of hyperhidrosis. J Am Acad Dermatol 1995;33:78-81.

18 Graham ANJ, Owens WA, McGuigan JA. Assessment of outcome after thoracoscopic sympathectomy for hyperhidrosis in a specialised unit. $J R$ Coll Surg Edinb 1996;41:160-3.

19 Gossot D, Kabiri H, Caliandro R, et al. Early complications of thoracic endoscopic sympathectomy: a prospective study of 940 procedures. Ann Thorac Surg 2001:71:1116-19.

20 Adams DCR, Wood SJ, Tulloh BR, et al. Endoscopic transthoracic sympathectomy: experience in the south west of England. Eur J Vasc Surg 1992;6:558-62.

21 Herbst F, Plas EG, Fugger R, et al. Endoscopic thoracic sympathectomy for primary hyperhidrosis of the upper limbs: a critical analysis and long-term results of 480 operations. Ann Surg 1994;220:86-90.

22 Fox AD, Hands L, Collin J. The results of thoracoscopic sympathetic trunk transection for palmar hyperhidrosis and sympathetic ganglionectomy for axillary hyperhidrosis. Eur J Vasc Endovasc Surg 1999;17:343-6.

23 Edmondson RA, Banerjee AK, Rennie JA. Endoscopic transthoracic sympathectomy in the treatment of hyperhidrosis. Ann Surg 1992;215:289-93.

24 Shelley WA, Florence R. Compensatory hyperhidrosis after sympathectomy. N Engl J Med 1960;263:1056-8.

\section{CALL FOR FILLERS}

The Postgraduate Medical Journal invites readers to contribute fillers for the journal. They can be on any topic likely to be of interest but we particularly welcome fillers on the following:

- Self help groups.

- Favourite books.

- Life defining moments or patients.

- Medical history.

Fillers, of around 250 words, can be emailed to the editor at pmj@btinternet.com for consideration. 